\title{
EFFECTIVENESS OF HYBRID AND PARTIALLY CONFINED CONCRETE SUBJECTED TO AXIAL COMPRESSIVE LOADING USING CFRP AND GFRP COMPOSITE MATERIALS
}

\author{
Youcef GHERNOUTI ${ }^{*}$, Bahia RABEHI ${ }^{1}$
}

\section{Abstract}

This paper presents the results of an experimental study that investigates the compression behavior of concrete and evaluates the effect of hybrid reinforcement by multiple geometries, and total and partial confinement, using CFRP and GFRP composite materials.

A total of nine (09) variants of concrete cylindrical specimens, including one (01) variant of unconfined concrete and eight (08) variants of confined concrete with different geometries were subjected to axial load compression.

The objectives of this study were to verify the applicability and effectiveness of partial and total confinement to improve the behavior of concrete, evaluate the effect of the hybrid confinement used, and obtain a typical reinforced model.

The results obtained clearly show the effectiveness of the hybrid confinement and partially confined concrete in improving the compressive strength and deformation of the concrete, so it is possible to replace CFRP total confinement by partially confined concrete with two CFRP layers or by a hybrid confinement with a CFRP layer in the central zone and GFRP layers on the top and bottom of the specimen.
Address

1 Dept. of Civil Engineering. Research Unit: Materials, Process and Environment. University M'Hamed Bougara of Boumerdes, Algeria

* Corresponding author: y.ghernouti@univ-boumerdes.dz

\section{Key words}

- Confinement

- Hybrid,

- CFRP

- GFRP,

- Compressive strength,

- Deformation.

\section{INTRODUCTION}

In recent years, the use of fiber-reinforced polymer (FRP) composites has drawn much attention in civil engineering; they are widely used for the repair and rehabilitation of existing structures due to their favorable properties such as their excellent strength/self-weight ratio, high durability, corrosion resistance, easy handling and application, speed of construction, and tremendous design flexibility. Rapid growth has been observed in the application of FRP confining jackets for the strengthening/retrofitting of reinforced concrete columns. Carbon FRP, glass FRP, and Aramid FRP are the most common FRP composites used commercially. Numerous experimental studies have been conducted to examine the performance of FRP composites in strengthening and retrofitting concrete columns; it has been demonstrated that both the compressive strength and deformability of concrete can be significantly increased by lateral confinement using FRP composite materials (Ben- zaid et al., 2010; Rabehi et al., 2014; Lim and Ozbakkaloglu, 2015 ; Benzaid et al., 2014; Benzaid et al., 2009; Berthet et al., 2005; Lam and Teng, 2003; Rochette and Labossière, 2000; Shahawy et al., 2000).

Recently, research efforts have been directed towards the application of FRP in new column constructions; they have been targeted at developing new reinforcing methods that use less FRP in concrete structures to reduce costs and that use hybrid composite materials with the idea of combining composite materials to achieve better performances from concrete in its strength, deformation and failure mode.

An experimental study was conducted by (Nain et al. 2017) to determine the cyclic compressive behavior of concrete confined with a new hybrid FRP system, with Large Rupture Strain FRP (LRS-FRP) inside, and with conventional glass FRP (GFRP) outside. The results showed that using LRS-FRP significantly improved the ductility of the confined concrete. However, any improvement in its strength was limited. The hybrid confinement improves both the ductility and strength. 
(WU et al., 2008) studied the performance of concrete cylinders confined with different types of FRP and hybrid FRP composites. Five different types of FRP composites were used: high strength CFRP, high modulus CFRP, Aramid FRP, Glass FRP (GF), and PBO FRP. The experimental parameters included different types of FRP sheets, the number of layers of the FRP sheets, and the different kinds of hybridization with two or three types of FRP composites.

The results obtained indicated that confinement could be effective in increasing the strength, ductility and energy absorption capacity of concrete cylinders. The ultimate strength of FRP-confined concrete can be improved by adding a high-strength FRP sheet to a high ductility FRP sheet. The ultimate strain remains the same as for the counterpart specimens confined only with the high ductility FRP sheet.

The work of (Li et al., 2013) presented an experiential study on concrete columns confined by three kinds of hybrid FRPs, including CFRP, BFRP and GFRP, with the main aim of the study being to explore the confining effect of the hybrid use of FRPs on concrete. The compressive strengths and stress-strain curves of concrete columns confined by HFRP were presented, based on which the performance of FRPs was demonstrated, and a stress-strain model of the concrete confined by HFRP was proposed as well. The test results showed that the bearing capacity and ductility of the concrete columns were efficiently improved through the hybrid FRP confinement.

(Lin and Chen, 2001) experimentally investigated the effects of a number of layers of reinforced carbon and glass fiber composites and the hybridization and stacking sequences of composites and reinforced regions by different composites (CFRP and GFRP) based on the strength of confined concrete cylinders subjected to uniaxial compression. The authors conclude that the strength of a confined concrete cylinder increases proportionally to the number of layers of the composites; this has also been shown by other researchers (Cui, 2009; Fardis and Khalili, 1981; Fardis and Khalili, 1982; Xiao and Wu, 2000; Konráðsson, 2011; Benzaid and al., 2008).

The authors recommended wrapping the concrete cylinder first with the more ductile composite. The reinforcement by different composites in distinct regions is not recommended.

The present paper is an additional contribution in this direction and aims at studying the compressive behavior of concrete columns strengthened with different configurations, partially or totally confined by CFRP and GFRP composites.

\section{EXPERIMENTAL PROGRAM}

\subsection{Materials used}

\subsubsection{Concrete mixture}

In this study, the experiments were carried out with only one concrete mixture, which was composed of sand $(0 / 4) \mathrm{mm}$, two types of gravel ( $3 / 8$ and $8 / 15) \mathrm{mm}$ and cement type CEM II 42.5. The specific gravity of the sand and coarse aggregates were 2.66 and 2.7 , respectively. The sand had a fineness modulus of 2.73 . The composition of the concrete was determined by the Dreux Gorisse method (George, 1998).

All the samples were cured for 28 days in water under a laboratory temperature of $22 \pm 3^{\circ} \mathrm{C}$. Afterwards, they were taken out and confined with different geometries of FRPs.

\subsubsection{FRP composites}

In this study, two types of FRP composite materials were selected for the confinement of the cylindrical concrete, a bidirectional GFRP and a unidirectional CFRP. The GFRP is made of continuous glass fi- ber type E with a weight of $262 \mathrm{~g} / \mathrm{m}^{2}$. The CFRP is a carbon fiber fabric (SIKA WRAP HEX 230C), with a weight of $183 \mathrm{~g} / \mathrm{m}^{2}$. The resin system that was used to bond the CFRP and GFRP was Sikadur-330. The mechanical properties of the FRP materials and the resin used are given in Table 1.

Tab. 1 Mechanical properties of FRP materials and resin (Ghernouti et al., 2012; Hadj Mostefa et al., 2015)

\begin{tabular}{|l|c|c|c|}
\hline & GFRP & CFRP & Resin \\
\hline Tensile strength (MPa) & $69-86$ & $345-690$ & $>30$ at 2 days and $20^{\circ} \mathrm{C}$ \\
\hline $\begin{array}{l}\text { Elastic modulus in } \\
\text { tension (GPa) }\end{array}$ & 74 & $>165$ & 4.5 at 7 days and $23^{\circ} \mathrm{C}$ \\
\hline $\begin{array}{l}\text { Ultimate elongation in } \\
\text { tensile (\%) }\end{array}$ & 4.5 & 1.7 & $/$ \\
\hline $\begin{array}{l}\text { Compressive stress } \\
\text { (MPa) }\end{array}$ & $/$ & $/$ & $>55$ at 2 days and $20^{\circ} \mathrm{C}$ \\
\hline
\end{tabular}

Tab. 2 Codes and confinement details of the test specimen

\begin{tabular}{|l|l|}
\hline Variants of confinement & Configuration and specimens code \\
\hline Unconfined concrete & $(U C)$ \\
\hline $\begin{array}{l}\text { Total confined concrete } \\
\text { With CFRP or GFRP }\end{array}$ \\
\hline $\begin{array}{l}\text { Partially confined con- } \\
\text { crete in central zone } \\
\text { with one (1) layer of } \\
\text { CFRP or GFRP }\end{array}$ \\
\hline $\begin{array}{l}\text { Hybrid confined } \\
\text { concrete with CFRP } \\
\text { and GFRP } \\
\text { Partially confined con- } \\
\text { with two (2) layer of } \\
\text { CFRP or GFRP }\end{array}$ \\
\hline
\end{tabular}

Carbon Fiber-Reinforced Polymer (CFRP)

Glass Fiber-Reinforced Polymer (GFRP) 


\subsection{Variants of the confinements}

The experimental program of this study included a total of twenty seven (27) plain concrete cylinders, each with a $110 \mathrm{~mm}$ diameter and a $220 \mathrm{~mm}$ height; these specimens were divided as follows:

- Three (3) unconfined concrete specimens (UC);

- Six (6) specimens, totally confined by a layer of FRP, in which three specimens were confined by a CFRP layer (C), and three others were confined by a GFRP layer $(\mathrm{G})$;

- Six (6) specimens, which were partially confined by a layer of FRP in the middle third of the specimen (central zone), in which three specimens were confined by a CFRP layer (C1), and three others were confined by a GFRP layer (G1);

- Six (6) specimens, partially confined by two layers of FRP in the middle third of the specimen (central zone), in which three specimens were confined by two CFRP layers (C2), and three others were confined by two GFRP layers (G2);

A summary of the test specimen codes and confinement details are given in Table 2 .

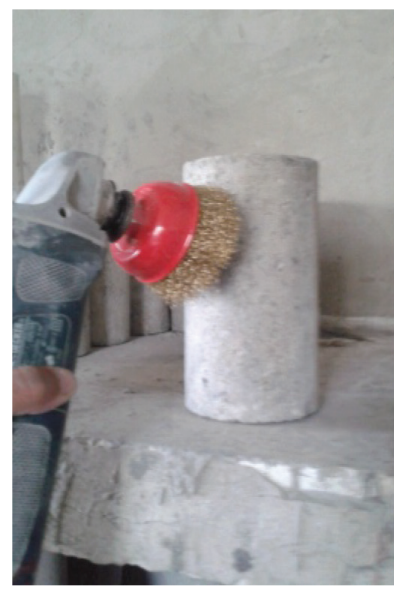

(a)
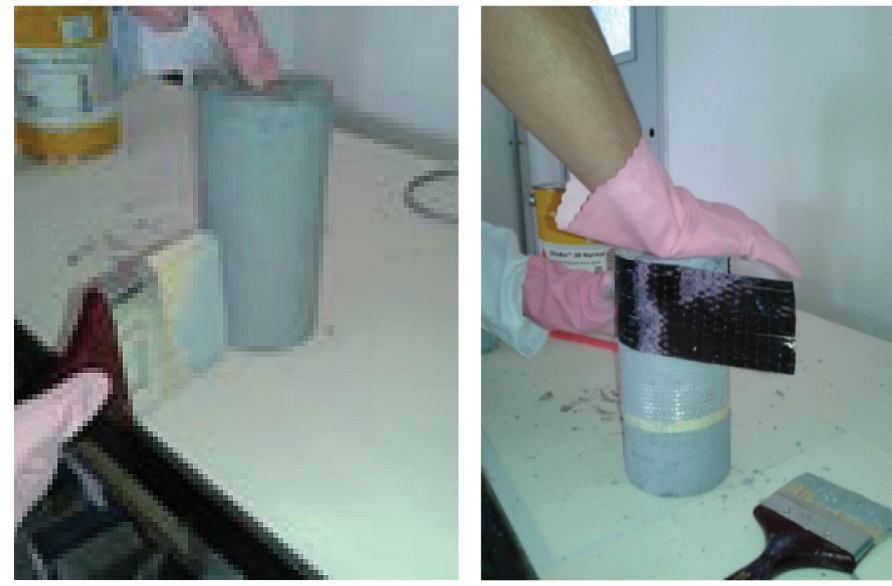

(b)

\subsection{Confinement of the specimens by FRPs}

At the age of 28 days, the surfaces of the specimens were cleaned and polished with a wire brush and then dusted with an aspirator.

The FRP composite materials were carefully cut to the desired dimensions. For the confining of the FRPs on the specimens, a $1 \mathrm{~mm}$ thick layer of the adhesive was applied to the surface; then the FRP was manually placed on the support. Finally, manual pressure was exerted on the composite using a squeegee (Figure 1).

Examples of the confined specimens are presented in Figure 2.

\subsection{Testing the specimens}

The compressive strength was determined in accordance with the NF EN 12390-3 standard. All the prepared specimens were loaded under a monotonic uni-axial compressive load up to failure by using a hydraulic testing machine (Toni technique) with a static loading capacity of $3000 \mathrm{kN}$. The loading was applied in terms of displacement control at a slow rate of $2.5 \mathrm{~mm} / \mathrm{s}$.

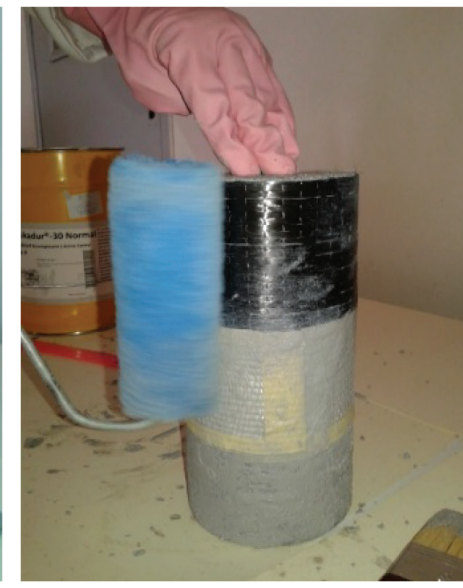

Fig 1 Confinement of the concrete specimen by FRP: (a) preparation of the concrete surface, (b) Application of resin and FRP materials on the concrete support

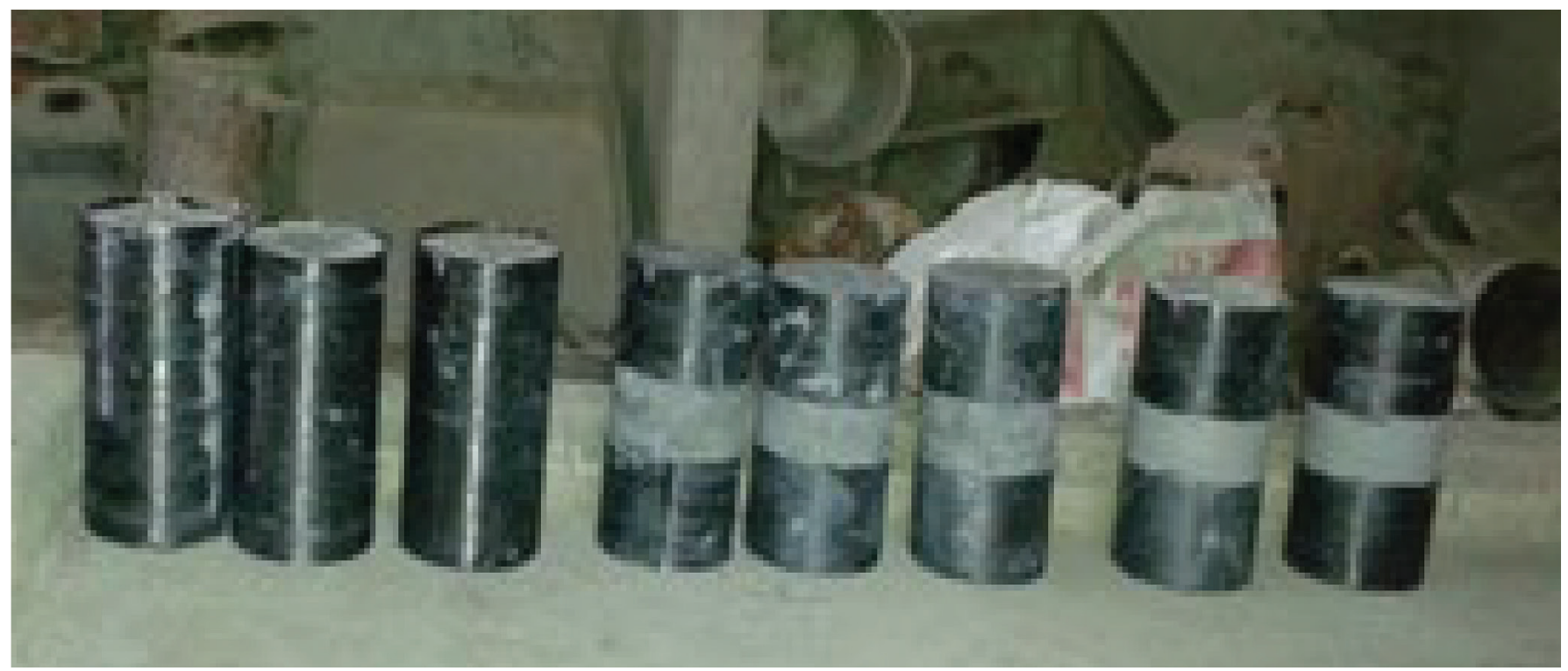

Fig. 2 Examples of confined specimens 


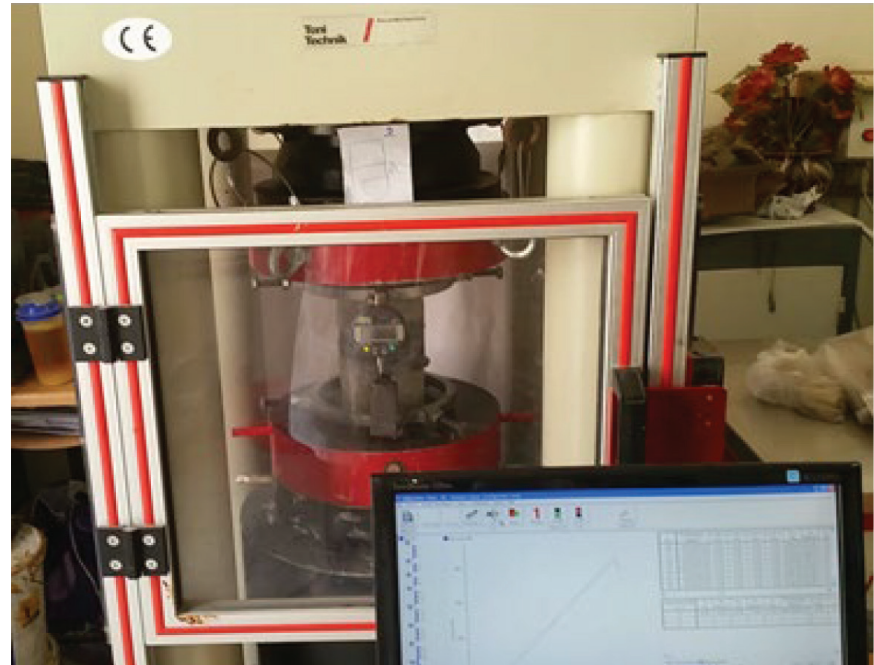

Fig. 3 Test setup and instrumentation

Before the testing, the end surface of the specimens was prepared to ensure the parallelism and flatness of the faces of the support. An extensometric comparator was fixed to the side face of the specimen at mid-height (Figure 3). The values of the compressive strength and the corresponding axial strain were simultaneously recorded.

\section{EXPERIMENTAL RESULTS AND DISCUSSION}

Table 3 presents a summary of the experimental test results, to wit, the compressive strength, corresponding strain, and elastic modulus of all the concrete specimens. We note that the compressive strength is from 29 to $47 \mathrm{Mpa}$; the corresponding strain varies from 1.62 to $6.7 \%$; and the elastic modulus is from 25 to $35 \mathrm{GPa}$. For all the confinement variants of the specimens, the ratios $\left(\mathrm{f}_{\mathrm{cc}} / \mathrm{f}_{\mathrm{co}}\right),\left(\varepsilon_{\mathrm{cc}} / \varepsilon_{\mathrm{co}}\right)$ and $\left(E_{c c} / E_{c o}\right)$ are always significant; they present values superior to one, which shows the effectiveness of the confinement of the concrete by the different composite materials in the improvement of the mechanical properties, whatever the geometry of the confinement.

Tab 3 Mechanical properties of the unconfined and confined concrete

\begin{tabular}{|c|c|c|c|c|c|c|c|c|c|}
\hline & \multicolumn{3}{|c|}{$\begin{array}{c}\text { Unconfined } \\
\text { concrete }\end{array}$} & \multicolumn{6}{|c|}{ Confined concrete } \\
\hline & $\begin{array}{c}f_{c o} \\
(\mathrm{MPa})\end{array}$ & $\begin{array}{l}\varepsilon_{c o} \\
(\%)\end{array}$ & $\begin{array}{l}E_{c o} \\
(G P a)\end{array}$ & $\begin{array}{c}f_{c c} \\
(\mathrm{MPa} a\end{array}$ & $\begin{array}{l}\varepsilon_{c c} \\
(\%)\end{array}$ & $\begin{array}{l}E_{c c} \\
(G P a)\end{array}$ & $f_{c c}, f_{c o}$ & $\varepsilon_{c c} / \varepsilon_{c o}$ & $E_{c c} / E_{c c}$ \\
\hline$U C$ & 29 & 1.62 & 25 & - & - & - & - & - & - \\
\hline C & & & & 47 & 6.7 & 33 & 1.62 & 4.13 & 1.32 \\
\hline$G$ & & & & 40 & 3.08 & 35 & 1.39 & 1.90 & 1.4 \\
\hline$C 1$ & & & & 41 & 3.18 & 31 & 1.41 & 1.96 & 1.24 \\
\hline$G 1$ & & & & 40 & 3.3 & 28 & 1.39 & 2.04 & 1.12 \\
\hline$C 2$ & & & & 45 & 4.32 & 28 & 1.55 & 2.66 & 1.12 \\
\hline$G 2$ & & & & 42 & 3.8 & 31 & 1.45 & 2.34 & 1.24 \\
\hline$C G C$ & & & & 37 & 3.37 & 34 & 1.27 & 2.08 & 1.36 \\
\hline$G C G$ & & & & 44 & 4.53 & 28 & 1.52 & 2.80 & 1.12 \\
\hline
\end{tabular}

\subsection{Effect of confinement by carbon fiber composites (CFRP)}

The axial stress versus the axial strain curves of the totally or partially confined specimens by CFRP in comparison with the unconfined concrete (control specimens) are shown in Figure 4.

The confinement by the carbon fiber fabric (CFRP) can significantly increase the ultimate load and axial strain of concrete but at different degrees according to the geometry of the confinement and number of layers. The totally confined specimens $(\mathrm{C})$ gave the best results; gains of $62 \%$ in strength, $313 \%$ in deformation, and $32 \%$ in Young's modulus were recorded. The effectiveness of the improvement of the mechanical properties of concrete confined by carbon fiber fabric has been proven by quite a few authors (Lam and Teng, 2004; Li et al., 2002; Harries and al, 2002; Li and Hadi, 2003; Xiao and Wu, 2003). However, the specimens partially confined by CFRP give different results compared to the totally confined specimens; the partial confinement of concrete by two layers of CFRP in the middle zone (C2) shows similar results for compressive strength as the total confinement by a single layer (C); the difference is $4 \%$, while as to the partial confinement of the concrete by a single layer in the central zone $(\mathrm{C} 1)$, the compressive strength decreased by $15 \%$ compared to the totally confined specimens.

It is clear that the confinement by the carbon fiber fabric is more effective and attractive in terms of mechanical behavior. We can observe in Figure 4 that the mechanical behavior of the confined specimens compared to the unconfined specimens is different. The rigidity of the confined concrete specimens is greater than that of the other specimens (the control concrete). The plastic zone of the totally CFRP confined specimens is also greater than that of the other specimens. It is clear that the improvement of the maximum deformation is considerable. The value of this deformation is approximately $6.7 \%$ in the case of the totally confined concrete specimens. This improvement may be due to the characteristics of the carbon fiber fabric, which has good tensile strength and a high elastic modulus. The primary role of CFRP composite materials is to confine the concrete by giving it a greater reserve of strength and ductility.

For the partial confinement of the concrete, the good results obtained in the case of the partial confinement by two carbon layers in the central zone (C2), which are similar to total confinement, are due to the presence of a large quantity (two layers) of CFRP in the central zone of the specimen, which represents the site of the concentrated load.

\subsection{Effect of confinement by glass fiber composites (GFRP)}

The results of the compression tests for the stress, strain and Young's modulus of the specimens that are confined using glass fiber

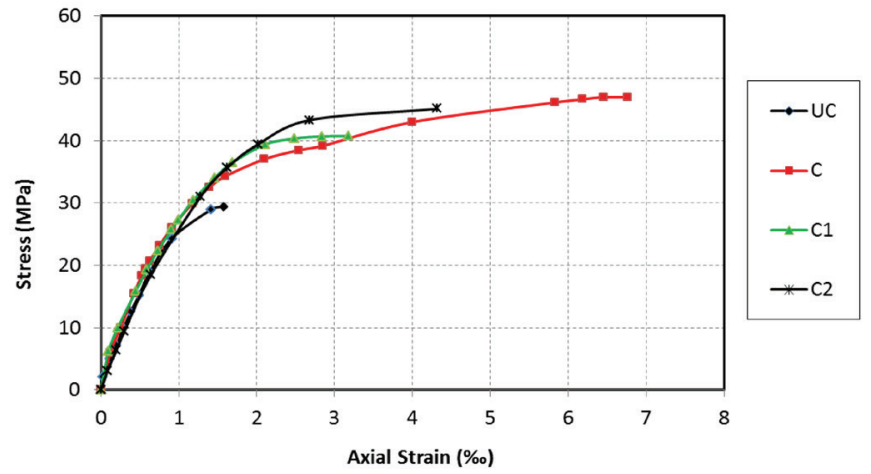

Figure 4. Stress- strain curves of the specimen confined by CFRP in comparison with the unconfined concrete. 


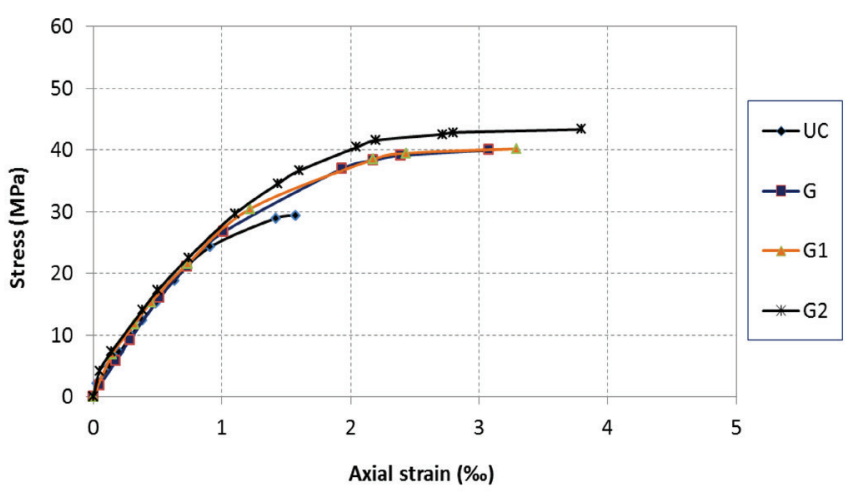

Fig. 5 Stress- strain curves of the specimens confined by GFRP in comparison with the unconfined concrete

fabrics by different geometries, compared to the unconfined concrete specimen, are shown in Table 2 and Figure 5.

The results obtained show that the confinement using the glass fabric GFRP gives good resistance and deformability compared to the control concrete regardless of the geometry of the confinement. We note that the total confinement of the specimens with GFRP did not have a significant effect in comparison with the partial confinement with one or two layers in the central zone; the compressive strength results are similar. The gain in the compressive strength of the totally confined concrete specimens compared to the control concrete is on the order of $39 \%$, while the gain was $39 \%$ and $45 \%$ for the specimens partially confined in the central zone with one and two layers of GFRP, respectively.

The effect of the hybrid confinement by a glass layer in the central zone and a carbon layer at the top and bottom of the specimens (CGC) on the compressive strength of the concrete remains relatively low, about $7.5 \%$, compared to the specimens totally confined by GFRP $(\mathrm{G})$ or the specimens partially wrapped at the center ("G1"); this is probably due to the lower strength of the pure concrete cylinder (without being wrapped by CFRP and GFRP).

The concrete specimens partially confined by two layers of GFRP in the central zone give the maximum deformation. The value of this deformation is approximately $3.8 \%$.

Finally, it can be concluded that the confinement by CFRP of concrete specimens subjected to axial compression loading, regardless of the geometry of the confinement, is more effective, more attractive and very beneficial compared to the confinement by GFRP; this is due to the very interesting properties of the carbon fiber fabric, which has good tensile strength and a high modulus of elasticity, compared to the glass fiber fabric.

\subsection{Effect of hybrid confinement by composite materials (CFRP and GFRP)}

\subsubsection{Comparison between hybrid confinement and total confinement}

In this part, we present the effects of hybrid confinement with different configurations, using the glass and carbon composites.

The values of the compressive strength, deformation and elastic modulus of these specimens are presented in Table 2. The results obtained clearly show the positive effects of hybrid confinement in improving the behavior of the concrete by using glass and carbon fibers, according to the geometry of the confinement. The strength and deformation gains are respectively $52 \%$ and $180 \%$ for the hybrid confined concrete with a CFRP layer in the central zone and a GFRP

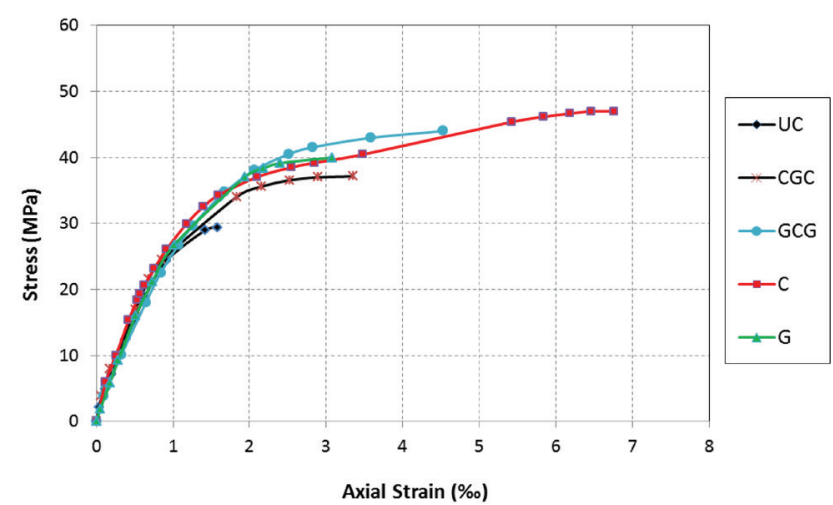

Fig 6 Stress-strain curves of hybrid confined specimens in comparison with the totally confined concrete and unconfined concrete

layer at the bottom and at the top (GCG), compared to the control concrete (UC). In the case of the specimens (CGC) confined with a GFRP layer in the central zone and a CFRP layer at the bottom and top, the gains in compressive strength and deformation are less important; they are on the order of $27 \%$ and $108 \%$ respectively. Comparing the hybrid confined specimens to the totally confined specimens (Figure 6), we note that the specimens confined with a carbon layer in the central zone and a glass layer at the top and bottom (GCG) show better values of compressive strength and deformation compared to the specimens totally confined with the fiber glass $(\mathrm{G})$, and close to that of the specimens totally confined with the carbon fiber $(\mathrm{C})$, the difference in the resistance is $6 \%$. Indeed, we can conclude from these results that the effect of totally confined concrete by a layer of carbon fabric (CFRP) is similar to the effect of a partially hybrid confinement by a layer of CFRP in the central zone and a GFRP layer at the top and bottom, which means that the hybridization played an important economic role, as it allowed us to replace the upper and lower parts confined by CFRP carbon with glass fabric GFRP.

The effect of the hybrid confinement by a glass layer in the central zone and a carbon layer at the top and bottom on the compressive strength of the concrete remains relatively low compared to the total confinement; this is due to the absence of the CFRP layer in the central zone of the specimen, which represents the site of a concentrated load.

\subsubsection{Comparison with the hybrid confinement and partially confined concrete}

Figures 7 and 8 show the axial stress versus the axial strain curves of the control concrete and hybrid confined concrete in comparison with the partially CFRP and GFRP confined concrete at the central zone of the specimens respectively.

The results obtained (Table 2) show that the confinement of the concrete specimens using glass fabric in the central zone, whatever the geometry of the confinement, either hybrid or partial confinement with one or two layers of GFRP, gives similar values of the compressive strength, deformation and elastic modulus; on the other hand, the hybrid confined concrete with a CFRP layer in the central zone and GFRP layer at the bottom and top (GCG), as well as the concrete specimens partially confined with two layers of carbon fiber in the central zone $(\mathrm{C} 2)$, show better values of compressive strength and deformation compared to all the specimens, either hybrid or partially confined with glass fiber at the central zone. We notice that the effect of the partially confined concrete with one layer of CFRP in the central zone is similar to all the specimens, whether hybrid or partially confined with glass fiber at the central zone.

Indeed, we can conclude from these results that the partially confined effect of concrete by two layers of carbon fabric in the central 


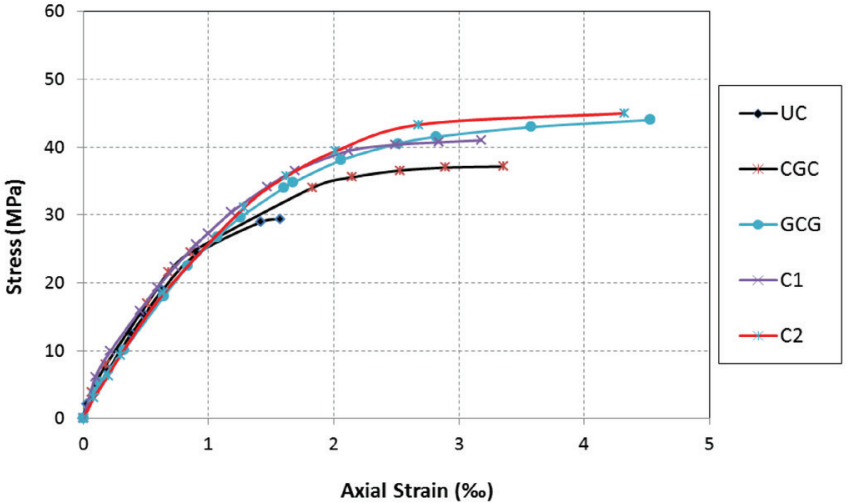

Fig. 7 Stress-strain curves of hybrid confined specimens in comparison with totally and partially confined concrete by CFRP zone (C2) is similar to the effect of a partially hybrid confinement by a layer of CFRP in the central zone and a GFRP layer at the top and bottom (GCG); the compressive strength is on the order of 45 and $44 \mathrm{MPa}$, respectively. These variants present the same elastic modulus of about $28 \mathrm{GPa}$.

The hybrid wrapping played an important economic and technical role; from a technical point of view, the hybrid confinement has a clearly positive effect in the improvement of the behavior of the concrete. Using glass and carbon fibers according to the geometry of confinement gives a better performance concerning the strengths and the deformability, which is probably due to the conjugation of the properties of each type of FRP.

Hybrid wrapping also played an important economic role; it allowed us to replace the upper and lower parts of the specimen confined by CFRP sheets with GFRP sheets. Since the totally confined effect of the concrete by a layer of carbon fabric (CFRP) is similar to the effect of hybrid confinement by a layer of CFRP in the middle and a GFRP layer at the top and bottom, the replacement of the CFRP layers by GFRP layers allows for the reduction of the cost of the reinforcement techniques.

\section{CONCLUSION}

The results of the testing program on the hybrid FRP confinement, with partial or total confinement of the concrete specimens according to the geometry can be summarized as follows:

- The totally confined specimens by CFRP $(\mathrm{C})$ gave the best results, i.e., gains of $62 \%$ in strength, $313 \%$ in deformation and $32 \%$ in the Young's modulus were recorded in comparison with the unconfined concrete.

- The partial confinement of the concrete by two layers of CFRP in the central zone (C2) shows similar results for the compressive strength in comparison with the total confinement by a single layer $(\mathrm{C})$; the difference is $4 \%$, while as to the partial confinement of the concrete by a single layer in the central zone (C1), the compressive strength decreased by $15 \%$ compared to the totally confined specimens.

- The total confinement of the specimens with GFRP did not have a significant effect in comparison with the partial confinement with one or two layers in the central zone; the compressive strength results are similar. The gain in compressive strength of the totally confined concrete specimens compared to the control concrete is on the order of $39 \%$, while the gain is $39 \%$ and $45 \%$ for the specimens partially confined in the central zone with one and two layers of GFRP, respectively.

- Hybrid confinement in using glass and carbon fibers has a clear-

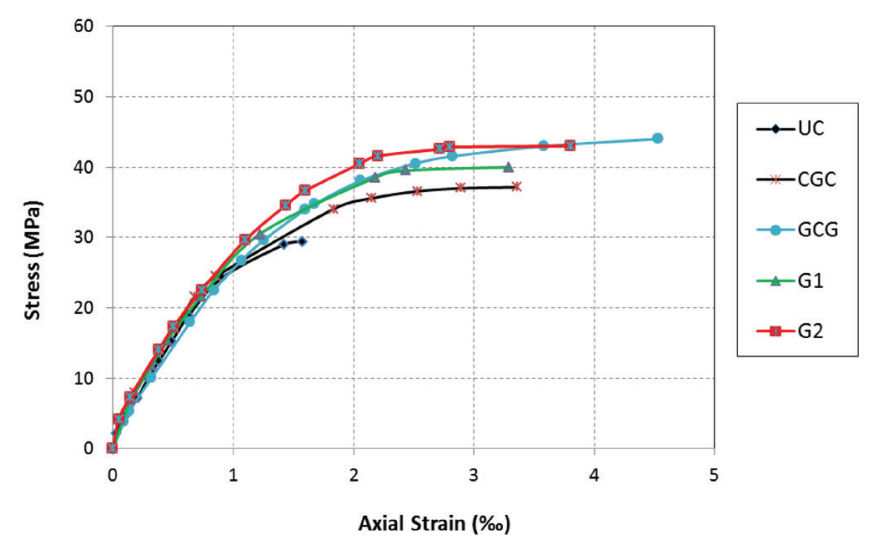

Fig. 8 Stress-strain curves of hybrid confined specimens in comparison with the partially confined concrete by GFRP

ly positive effect in improvement of the concrete's behavior, according to the geometry of the confinement. The strength and deformation gains are respectively $52 \%$ and $180 \%$, for the hybrid confined concrete with a CFRP layer in the central zone and GFRP layer on the bottom and at the top (GCG), compared to the control concrete (UC). While for the specimens (CGC) confined with a GFRP layer in the central zone and a CFRP layer in the bottom and top, the gains in compressive strength and deformation are less important; they are on the order of $27 \%$ and $108 \%$, respectively.

- The specimens confined with a carbon layer in the central zone and a glass layer on the top and bottom (GCG) show better values of compressive strength and deformation compared to the specimens totally confined with fiber glass $(\mathrm{G})$, and close to that of the specimens totally confined with carbon fiber $(\mathrm{C})$; the difference in resistance is $6 \%$, which means that hybridization played an important economic role, as it allowed us to replace the upper and lower parts confined by the CFRP carbon with glass fabric GFRP.

- The partially confined effect of the concrete by two layers of carbon fabric in the central zone $(\mathrm{C} 2)$ is similar to the effect of the partially hybrid confinement by a layer of CFRP in the central zone and a GFRP layer at the top and bottom (GCG)

Finally, we note that it is possible to replace a CFRP total confinement by the partially confined concrete with two CFRP layers in the central zone or by hybrid confinement with a CFRP layer in the middle and GFRP layers in the top and bottom of the specimen. 


\section{REFERENCES}

Benzaid, R. - Chikh, N. E. - Mesbah, H. (2008) Behaviour of square concrete column confined with GFRP composite warp. Journal of engineering and management, Vol.14, No.2, pp. 115-120

Benzaid, R. - Chikh, N. E. - Mesbah, H.A. (2009) Study of the compressive behavior of short concrete columns confined by fiber reinforced composite. The Arabian Journal for Science and Engineering. Vol. 34, No. 1B, pp. 15-26.

Benzaid, R. - Mesbah, H. A. - Chikh, N. E. (2010) FRP-confined concrete cylinders: Axial compression experiments and strength model. J. Reinf. Plast. Compos. 29, pp. 2469-2488.

Benzaid, R. - Mesbah, H. A. (2014) The confinement of concrete in compression using CFRP composites - effective design equations. Journal of civil engineering and management. Vol. 20, No. 5, pp. 632-648.

Berthet, J. F. - Ferrier, E. - Hamelin, P. (2005) Compressive behavior of concrete externally confined by composite jackets. Part A: Experimental study. Construction and Building Materials, Vol. 19, No. 3, pp. 223-232.

Cui, C. (2009) Behaviour of Normal and High Strength Concrete Confined with Fibre Reinforced Polymers (FRP). A thesis submitted in conformity with the requirements for the degree of Doctor of Philosophy, Department of Civil Engineering, University of Toronto, Canada.

Fardis, M. N. - Khalili, H.H. (1981) Concrete Encased in Fibreglass-Reinforced Plastic. ACI Journal, Vol.78, No. 6, pp. 440-446.

Fardis, M. N. - Khalili, H. H. (1982) FRP-Encased Concrete as a Structural Material. Magazine of Concrete Research, Vol. 34, No.121, pp. 191-202.

George, D. - Jean, F. (1998) Nouveau guide du béton et de ses constituants [New guide of concrete and its constituents]. Paris: Edition eyrolles.

Ghernouti, Y. - Li, A. - Rabehi, B. (2012) Effectiveness of repair on damaged concrete columns by using fiber-reinforced polymer composite and increasing concrete section. J. Reinf. Plast. Compos, Vol. 31, No. 23, pp. 1616-1629.

Hadj Mostefa, A. - Ghernouti, Y. - Sebaibi, Y. (2015) Effectiveness of cement and plaster layers in protection of FRP confined concrete exposed to high temperatures. Journal of Adhesion Science and Technology, Vol. 29, No. 9, pp. 839-860.

Harries, K. A. -Kharel, G. (2002) Experimental Investigation of the Behavior of Variably Confined Concrete. Cement and Concrete Research, Vol. 33, No. 6, pp. 873-880.

Konráðsson, A. (2011). "Experimental Research on BFRP Confined Concrete Columns", Thesis in civil engineering with emphasis on structural engineering submitted to the School of Science and Engineering at Reykjavík University in partial fulfillment of the requirements for the degree of Master of Science.

Lam, L. - Teng, J. G. (2003) Design-oriented stress-strain model for FRP-confined concrete. Construction and Building Materials, Vol. 17, Nos. 6-7, pp. 471-489.
Lam, L. - Teng, J. G. (2004) Ultimate Condition of Fiber Reinforced Polymer-Confined Concrete. Journal of Composites for Construction, Vol. 8, No. 6, pp. 539-548.

Li, Y. - Hadi, M. N. S. (2003) Behaviour of Externally Confined High-Strength Concrete Columns under Eccentric Loading. Composites for Construction, Vol. 62, No. 2, pp. 145-153.

Li, Y. - Lin, C. - Sung, Y. (2002) Compressive Behavior of Concrete Confined by Various Types of FRP Composite Jackets. Mechanics of Materials, Vol. 35, No. 3, pp. 603-619.

Li L.J. -Xu, S. D. -Zeng, L. - Guo, Y.C. (2013) Compressive behavior of hybrid FRP confined concrete columns. The 2013 World Congress on Advances in structural engineering and mechanics (ASEM13), Sept 8-12, Jeju, Korea, pp. 468-488

Lim, J. C. -Ozbakkaloglu, T. (2015) Influence of concrete age on stress-strain behavior of FRP-confined normal-and highstrength concrete. Construction and Building Materials, Vol. 82, pp. 61-70.

Lin, H. J. - Chen, C. T. (2001) Strength of Concrete Cylinder Confined by Composite Materials. Journal of reinforced plastics and composites, Vol. 20, No. 18, pp. 1577-1600

Nain, M. - Abdulazeez, M. M. - ElGawady, M. A. (2017) Cyclic Compression Behavior of Concrete-Filled Hybrid Large Rupture Strain FRP Tubes. Fourth International Conference on Smart Monitoring, Assessment and Rehabilitation of Civil Structures (SMAR), 13-15 Sept, Zurich, Switzerland.

Rabehi, B. - Ghernouti, Y, -Alex, L. - Boumchedda, K. (2014) Comparative behavior under compression of concrete columns repaired by fiber reinforced polymer (FRP) jacketing and ultra-high performance fiber reinforced concrete (UHPFRC). Journal of Adhesion Science and Technology, Vol. 28, Nos. 22-23, pp. 2327-2346.

Rochette, P. - Labossière, P. (2000) Axial testing of rectangular column models confined with composites. Journal of Composites for Construction, Vol. 4, No. 3, pp. 129-136.

Shahawy, M. - Mirmiran, A. - Beitleman, T. (2000) Tests and modeling of carbon-wrapped concrete columns. Composites Part B: Engineering, Vol. 31, Nos. 6-7, pp. 471-480.

WU, G. - WU, Z. S. - LU, Z. T. - ANDO, Y. B. (2008) Structural Performance of Concrete Confined with Hybrid FRP Composites. Journal of reinforced plastics and composites, Vol. 27, No. 12, pp. 1323-1348.

Xiao, Y. - Wu, H. (2000) Compressive Behavior of Confined Concrete by Carbon Fiber Composite Jackets. Journal of Materials in Civil Engineering, Vol.12, No. 2, pp.139-146.

Xiao, Y. - Wu, H. (2003) A Constitutive Model for Concrete Confinement with Carbon Fiber Reinforced Plastics. Journal of Reinforced Plastics and Composites, Vol. 22, No. 13, pp. 1187-1201. 